\title{
$\gamma$-Ionylidene-type sesquiterpenoids possessing antimicrobial activity against Porphyromonas gingivalis from Phellinus linteus and their absolute structure determination
}

\author{
Tatsuya Shirahata ${ }^{1,4}$, Chieko Ino ${ }^{1,4}$, Fumi Mizuno ${ }^{1}$, Yoshihisa Asada ${ }^{1}$, Masao Hirotani ${ }^{1}$, George A Petersson ${ }^{2}$, \\ Satoshi Ōmura ${ }^{2,3}$, Takafumi Yoshikawa ${ }^{1}$ and Yoshinori Kobayashi ${ }^{1}$
}

The Journal of Antibiotics (2017) 70, 695-698; doi:10.1038/ja.2017.35; published online 22 March 2017

\section{INTRODUCTION}

The oral bacteria Porphyromonas gingivalis ( $P$. gingivalis) is well known as a periodontal pathogen. It not only causes periodontal disease but also plays a role in systemic disease including diabetes, respiratory illness, pregnancy complications and heart disease. ${ }^{1} P$. gingivalis has been identified as a key pathogen contributing to chronic periodontitis; its establishment in subgingival sites induces an inflammatory response that leads to gingival tissue destruction and the progressive loss of alveolar bone around the teeth. ${ }^{2}$ Hence, discovering new growth inhibitors for these oral periodontal pathogens is of potential importance. Among the different potential sources of new bioactive compounds, mushrooms are of great interest because they contain a number of secondary metabolites with unique structures and interesting biological activities. Thus, mushrooms have been used as a valuable resource for the discovery of lead compounds in medicinal research. ${ }^{3}$

The medicinal mushroom Phellinus linteus ( $P$. linteus, 'Meshimakobu' in Japanese), a member of the Hymenochaetaceae family, is a well-known fungus that is widely used in China, Korea and other Asian countries. Many studies have reported that this mushroom exhibits various pharmacological effects on several ailments including tumors, diabetes, inflammation and obesity. ${ }^{4}$ Experimental demonstrations of antitumor, ${ }^{5}$ immunomodulatory, ${ }^{6}$ anti-inflammatory ${ }^{7}$ and antioxidant ${ }^{8}$ activities of $P$. linteus have also been reported. Moreover, a large number of bioactive compounds have been isolated and extracted from this medicinal mushroom. Some other classes of mushrooms also contain compounds (including polysaccharides, flavones, triterpenes and phenols) that have been reported to be responsible for various bioactivities exhibited by $P$. linteus. ${ }^{9-12}$ Components in fruiting bodies and mycelia can be differentiated because the contents in $P$. linteus parasitizing on the trunk of
Morus alba L. are noticeably higher than those on other trees. Therefore, we supposed that an isolation study based on $P$. linteus would be suitable for medical research.

In the course of our search for natural products with antimicrobial activity against $P$. gingivalis, the $\mathrm{MeOH}$ extract of the fruiting bodies of $P$. linteus was found to exhibit antimicrobial activity against $P$. gingivalis. A fractionation study on the $\mathrm{MeOH}$ extract of $P$. linteus resulted in the isolation of two known $\gamma$-ionylidene sesquiterpenoids, (-)-trans- $\gamma$-monocyclofarnesol (1) and $(+)-\gamma$-ionylideneacetic acid (2), as well as a new compound, Phellidene E (3). In this paper, we report the structures of $\mathbf{1}, \mathbf{2}$ and 3 together with their antimicrobial activities against $P$. gingivalis. (Figure 1)

\section{RESULTS AND DISCUSSION}

The cultured mycelia of $P$. linteus were extracted sequentially with methanol at room temperature. The concentrated methanolic extract was diluted with distilled water and partitioned with chloroform and ethyl acetate. Each fraction was dried in vacuo. The AcOEt extract was chromatographed on silica gel and separated into fractions 1-10. The chloroform extract was chromatographed on silica gel and separated into fractions 1-10. Further purification by silica gel column chromatography and reversed-phase HPLC afforded known compounds 1, 2 and new compound 3.

Compound 1, $[\alpha]_{\mathrm{D}}-6.8^{\circ}$, was afforded as a colorless oil. The molecular formula $\mathrm{C}_{15} \mathrm{H}_{26} \mathrm{O}$ was determined from HR-FAB-MS data. The IR spectrum displayed absorptions at $3421 \mathrm{~cm}^{-1}$ (-OH group) and $1643 \mathrm{~cm}^{-1}$ (double bond). The ${ }^{1} \mathrm{H}$ and ${ }^{13} \mathrm{C}$ NMR spectra were identical to those reported in literature for $(+)$-trans- $\gamma$ monocyclofarnesol. ${ }^{13,14}$ However, the value of $\alpha_{\mathrm{D}}[\alpha]_{\mathrm{D}}\left(+18.2^{\circ}\right)$ reported in the same paper was the opposite of that recorded for

${ }^{1}$ School of Pharmacy, Kitasato University, Tokyo, Japan; ${ }^{2}$ Department of Chemistry, Wesleyan University, Middletown, CT, USA and ${ }^{3}$ Graduate School of Infection Control Sciences and Kitasato Institute for Life Sciences, Kitasato University, Tokyo, Japan

${ }^{4}$ These authors contributed equally to this work.

Correspondence: Professor Y Kobayashi, School of Pharmacy, Kitasato Institute for Life Sciences, Kitasato University, 5-9-1 Shirokane, Minato-ku, Tokyo 108-8641, Japan. E-mail: kobayashiy@pharm.kitasato-u.ac.jp

Received 8 November 2016; revised 3 February 2017; accepted 6 February 2017; published online 22 March 2017 


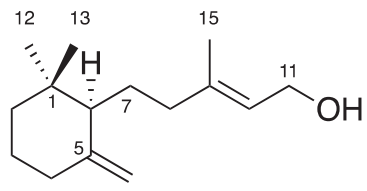

1

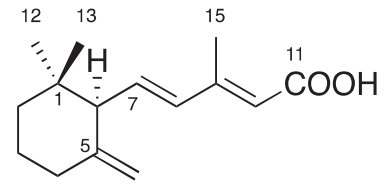

2

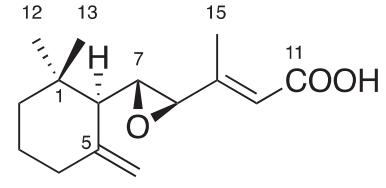

3

Figure 1 Structures of compounds (-)-trans- $\gamma$-monocyclofarnesol (1), (+)- $\gamma$-ionylideneacetic acid (2) and Phellidene E (3).

Table 1 NMR spectroscopic data $\left(400 \mathrm{MHz}, \mathrm{CDCl}_{3}\right)$ of compounds (-)-trans- $\gamma$-monocyclofarnesol (1), (+)- $\gamma$-ionylideneacetic acid (2) and Phellidene E (3)

\begin{tabular}{|c|c|c|c|c|c|c|}
\hline \multirow[b]{2}{*}{ Atom } & \multicolumn{2}{|l|}{1} & \multicolumn{2}{|l|}{2} & \multicolumn{2}{|l|}{3} \\
\hline & ${ }^{1} H$ & ${ }^{13} \mathrm{C}$ & ${ }^{1} H$ & ${ }^{13} \mathrm{C}$ & ${ }^{1} H$ & ${ }^{13} \mathrm{C}$ \\
\hline \multirow[t]{2}{*}{2} & 1.35 ddd $(14,8.5,5.5)$ & 39.0 & $1.35 \mathrm{ddd}(14.0,8.5,5.5)$ & 39.0 & $1.36 \mathrm{ddd}(13.0,7.0,6.0)$ & 39.1 \\
\hline & $1.50 \mathrm{ddd}(14,5.5,5.5)$ & & $1.50 \mathrm{ddd}(14.0,5.5,5.5)$ & & $1.50 \mathrm{~m}$ & \\
\hline 3 & $1.59 \mathrm{~m}$ & 23.2 & $1.59 \mathrm{~m}$ & 23.2 & $1.57 \mathrm{~m}$ & 23.4 \\
\hline 5 & & 149.6 & & 149.6 & & 148.0 \\
\hline 6 & $2.55 d(9.5)$ & 58.0 & $2.55 d(9.5)$ & 58.0 & 1.53 bd (8.5) & 57.2 \\
\hline 7 & $6.31 \mathrm{dd}(15.5,9.5)$ & 137.3 & $6.31 \mathrm{dd}(15.5,9.5)$ & 137.3 & $2.92 \mathrm{dd}(8.5,2.0)$ & 60.5 \\
\hline 8 & $6.14 \mathrm{~d}(15.5)$ & 135.3 & $6.14 \mathrm{~d}(15.5)$ & 135.3 & $3.04 \mathrm{dd}(2.0,1.0)$ & 59.3 \\
\hline 9 & & 154.9 & & 154.9 & & 157.6 \\
\hline \multirow[t]{2}{*}{14} & $4.54 \mathrm{~d}(1.5)$ & 109.0 & $4.54 \mathrm{~d}(1.5)$ & 109.0 & $4.52 \mathrm{~d}(1.0)$ & 109.2 \\
\hline & $4.76 \mathrm{~d}(1.5)$ & & $4.76 \mathrm{~d}(1.5)$ & & $4.80 \mathrm{dd}(1.0,1.0)$ & \\
\hline 15 & $2.33 \mathrm{~s}$ & 14.2 & $2.33 \mathrm{~s}$ & 14.2 & $2.11 \mathrm{~d}(1.0)$ & 15.0 \\
\hline
\end{tabular}

Abbreviations: bd, broad doublet; bs, broad singlet; bq, broad quartet; d, doublet; dd, double doublet; ddd, double double doublet; m, multiplet; s, singlet.

isolated compound $\mathbf{1}$. Thus, we assigned 1 as (-)-trans- $\gamma$ monocyclofarnesol (Table 1).

Compound 2, $[\alpha]_{\mathrm{D}}+11.7^{\circ}$, was afforded as a colorless oil. The molecular formula $\mathrm{C}_{15} \mathrm{H}_{22} \mathrm{O}_{2}$ was determined from HR-FAB-MS data. The IR spectrum displayed absorptions at 3420 (-OH group), 1680 ( $\alpha, \beta$-unsaturated carbonyl moiety), 1645 and $1600 \mathrm{~cm}^{-1}$ (trans-diene), and $1625 \mathrm{~cm}^{-1}$ (double bond). During a comparison with the ${ }^{1} \mathrm{H}$ NMR spectrum of $\mathbf{1}$, one olefinic proton peak was increased to assist the determination of structure $2[(2 E, 4 E)-\gamma$-ionylideneacetic acid]. The ${ }^{1} \mathrm{H}$ and ${ }^{13} \mathrm{C}$ NMR spectra of compound 2 were identical to those previously reported for $(2 E, 4 E)$ - $\gamma$-ionylideneacetic acid. ${ }^{15}$ Thus, the stereochemistry of 2 was expected to be similar to that of $\mathbf{1}$. We therefore assigned 2 as $(+)-(2 E, 4 E)-\gamma-$ ionylideneacetic acid.

Compound 3, $[\alpha]_{\mathrm{D}}+4.6^{\circ}$, was afforded as a colorless powder. The molecular formula $\mathrm{C}_{15} \mathrm{H}_{22} \mathrm{O}_{3}$ was determined from HR-FAB-MS data. The IR spectrum displayed absorptions at 3400 ( $-\mathrm{OH}$ group), 1650 and $1640 \mathrm{~cm}^{-1}$ (double bond), and $1696 \mathrm{~cm}^{-1}(\alpha, \beta$-unsaturated carbonyl moiety). The ${ }^{1} \mathrm{H}$ NMR spectra (Table 1 ) displayed typical resonances for two tertiary methyl groups at $\delta=0.99(3 \mathrm{H}, \mathrm{s}), 1.04$ $(3 \mathrm{H}, \mathrm{s})$, a vinyl methyl group at $\delta=2.11(3 \mathrm{H}, \mathrm{d}, J=1.0 \mathrm{~Hz})$, a terminal methylene group at $\delta=4.52(1 \mathrm{H}, \mathrm{d}, J=1.0 \mathrm{~Hz}), 4.80(1 \mathrm{H}, \mathrm{dd}, J=1.0$, $1.0 \mathrm{~Hz})$ and an oxymethylene group at $\delta=4.12(2 \mathrm{H}, \mathrm{d}, J=7.0 \mathrm{~Hz})$. In the ${ }^{13} \mathrm{C}$ NMR spectra, 15 signals similar to those observed for $\mathbf{1}$ and 2 were recorded. This suggests that the carbon skeleton of $\mathbf{3}$ is $\gamma$-ionylidene sesquiterpenoid. Comparison of the ${ }^{1} \mathrm{H}$ and ${ }^{13} \mathrm{C}$ NMR data of $\mathbf{3}$ with those of $\mathbf{2}$, revealed the disappearance of resonances for the double bond at $\mathrm{C} 7-\mathrm{C} 8$ in 2, instead of the observation of a resonance at $\delta 2.92(1 \mathrm{H}, \mathrm{dd}, J=8.5,2.0 \mathrm{~Hz}), \delta 3.04(1 \mathrm{H}, \mathrm{dd}, J=2.0$, $1.0 \mathrm{~Hz}), \delta 60.5(\mathrm{CH}), \delta 59.3(\mathrm{CH})$, in 3 , suggesting that an epoxide structure at $\mathrm{C} 7-\mathrm{C} 8$ in 3. Furthermore, detailed analyses of the HMBC spectra (Figure 2) confirmed the planar structure of 3 . The coupling constant of H-7 - H-8 $(8.5 \mathrm{~Hz})$ and the NOESY correlations between $\mathrm{H}-6 / \mathrm{H}_{3}-13, \mathrm{H}-7 / \mathrm{H}_{3}-14$ and $\mathrm{H}-6 / \mathrm{H}-8$ suggest that $\mathrm{H}-7$ and $\mathrm{H}-8$ exhibit an anti-periplanar conformation. The E-geometry of the olefin at the C9-C10 position was determined by NOESY correlations between $\mathrm{H}-10 / \mathrm{H}-15$. Furthermore, detailed analyses of the NOESY correlations of $\mathrm{H}-7 / \mathrm{H}-15$ and $\mathrm{H}-8 / \mathrm{H}-10$ were applied to determine the conformation of 3 (Figure 2). Thus, the relative configuration of 3 was elucidated as $6 R^{\star}, 7 R^{\star}, 8 R^{\star}$.

The absolute stereochemistry of $\mathbf{3}$ was deduced from a comparison between the electronic $\mathrm{CD}(\mathrm{ECD})^{16,17}$ and calculated spectra ${ }^{18}$ (Figure 3). The conformational analyses of 3 started from MM2 force field structures was further optimized by semi-empirical PM3 calculations, and was finally refined by density functional theory (DFT, B3LYP/6-31G level) calculations to yield additional relevant conformers. The ECD spectra of 3 were simulated using timedependent TD-density functional theory (B3LYP/DGDZVP level of theory) calculations on the relevant conformers.

A minimum value at a $260-280 \mathrm{~nm}$ area and a maximum value at a 220-240 $\mathrm{nm}$ area were observed as a result of the comparison between the experimental and calculated ECD spectra. In addition, the 

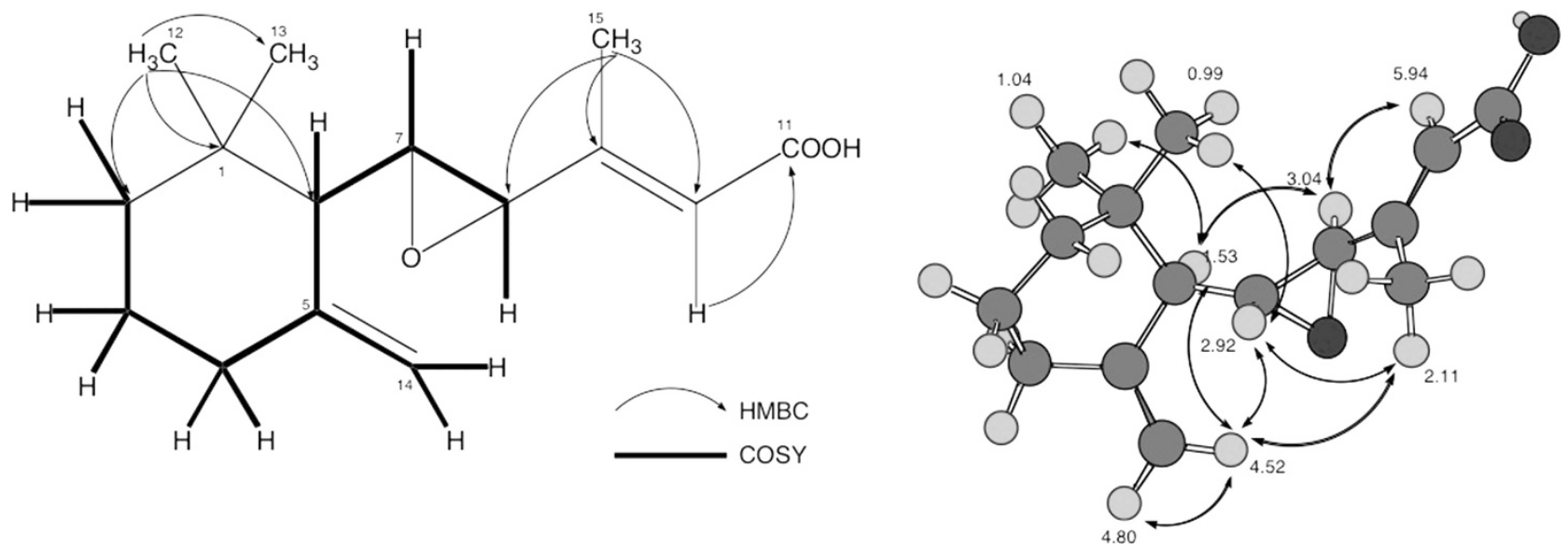

Figure 2 Key ${ }^{1} \mathrm{H}-{ }^{1} \mathrm{H}$ COSY and HMBC; and NOESY correlations of Phellidene E (3). A full color version of this figure is available at The Journal of Antibiotics journal online.

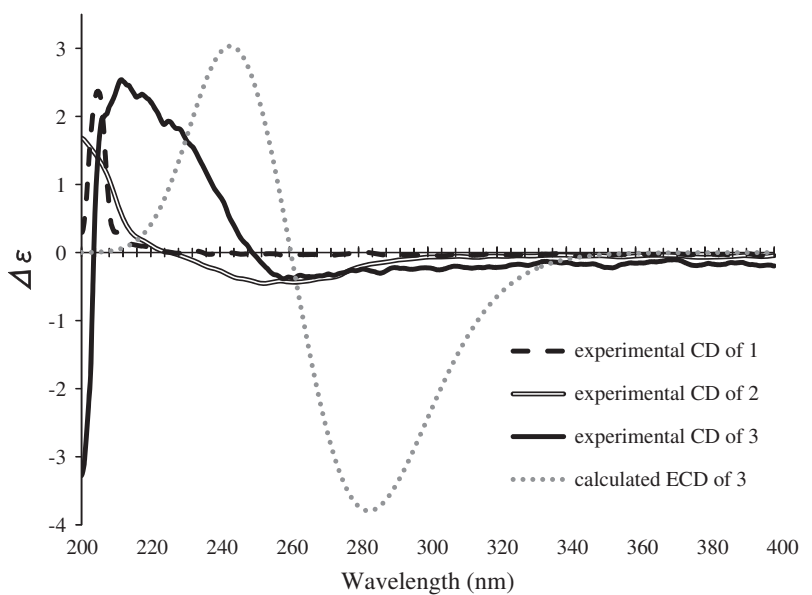

Figure 3 Experimental electronic $C D(E C D)$ spectra of $\gamma$-monocyclofarnesol (1), $\gamma$-ionylideneacetic acid (2) and Phellidene E (3) overlaid with the calculated ECD spectra.

measurement of the ECD spectrum of 1 and 2 resulted in the observation of a maximum value at a $200-240 \mathrm{~nm}$ area based on the stereochemistry at C6. Thus, the absolute stereochemistry of $\mathbf{3}$ was elucidated as $6 R, 7 R, 8 R$.

Compounds 1-3 were evaluated for their antibacterial activities against the periodontal bacteria $P$. gingivalis. The MIC was measured with hinokitiol and triclosan as positive controls (MIC: 25.0, $3.1 \mu \mathrm{g} \mathrm{ml}^{-1}$, respectively, Table 2). Although compounds 2 and 3 exhibited weak effects on the growth of $P$. gingivalis, compound 1 markedly inhibited its growth (MIC: $5.9 \mu \mathrm{g} \mathrm{ml}^{-1}$ ). These results support our hypothesis that the hydrophobic alkyl chain is an important moiety for the activity of $\gamma$-ionylidene sesquiterpenoid against $P$. gingivalis.

In conclusion, a new $\gamma$-ionylidene sesquiterpenoid (3) and two previously known $\gamma$-ionylidene sesquiterpenoid (1 and $\mathbf{2}$ ) were isolated from the fruiting bodies of $P$. linteus. Among these compounds, compound 1 exhibited potent antimicrobial activity against the oral pathogen $P$. gingivalis. Further studies are warranted to confirm the ability of products containing compound 3, such as mouthwash, toothpaste and chewing gum, to alter the composition of oral microflora in humans, thereby improving their oral health.
Table 2 Antibacterial activity of sesquiterpenes against Porphyromonas gingivalis ( $P$. gingivalis)

\begin{tabular}{lc} 
Compound & $M / C\left(\mu \mathrm{ml}^{-1}\right)$ \\
\hline$\gamma$-lonylidenes & \\
$\gamma$-monocyclofarnesol (1) & 5.9 \\
$\gamma$-ionylideneacetic acid (2) & 34.1 \\
Phellidene E (3) & 155 \\
Hinokitiol & 25.0 \\
Triclosan & 3.13 \\
\hline
\end{tabular}

\section{EXPERIMENTAL SECTION}

General information

Optical rotations $\left([\alpha]_{\mathrm{D}}\right)$ were measured on a JASCO DIP-1000 digital polarimeter (Tokyo, Japan). IR and UV spectra were recorded on a JASCO density functional theory/IR 460 infrared (Tokyo, Japan) and a Hitachi U-2800 spectrophotometer (Tokyo, Japan), respectively. ECD data were recorded on a JASCO J720 (Tokyo, Japan). Positive and negative ion HR-FAB-MS measurements were recorded on JEOL JMSAX505 HA and JMS-700 MS stations (Tokyo, Japan). EI-MS data were measured on a JEOL JMS-AX505 (Tokyo, Japan). ${ }^{1} \mathrm{H}$ and ${ }^{13} \mathrm{C}$ NMR experiments were performed on a Varian XL-400 (Palo Alto, CA, USA). The chemical shifts are expressed in p.p.m. downfield from the internal solvent peaks for $\mathrm{CHCl}_{3}$ (7.26 p.p.m., ${ }^{1} \mathrm{H}$ NMR), $\mathrm{CH}_{3} \mathrm{OH}$ (3.31, 4.84 p.p.m., ${ }^{1} \mathrm{H} \mathrm{NMR}$ ), $\mathrm{CDCl}_{3}$ (77.0 p.p.m., ${ }^{13} \mathrm{C} \mathrm{NMR}$ ) or $\mathrm{CD}_{3} \mathrm{OD}$ (49.0 p.p.m., ${ }^{13} \mathrm{C} \mathrm{NMR}$ ) and $J$ values were measured in Hertz. The coupling patterns are denoted as s (singlet), d (doublet), dd (double doublet), ddd (double double doublet), $\mathrm{t}$ (triplet), dt (double triplet), q (quartet), m (multiplet) or br (broad). HPLC analysis was carried out using a Shimadzu SPD-10AV UV-vis detector (Kyoto, Japan) and a Waters HPLC-pump (Waters 515, Milford, MA, USA, $\mathrm{UV} ; 254 \mathrm{~nm}$ ) with a $\mu$-BONDASPHERE $5 \mu$ C18-100 $\AA$ column $(5 \mu \mathrm{m}, 19 \phi \times 150 \mathrm{~mm})$. Pre-coated silica gel plates with a fluorescent indicator (Merck 60 F254, Darmstadt, Germany) were used for analytical and preparative thin layer chromatography. Flash column chromatography was carried out with silica gel (Kanto Chemical, Tokyo, Japan, silica gel 60N, spherical neutral, $0.040-0.050 \mathrm{~mm}$, Cat. No. 37 563-84). 


\section{Culture conditions for $P$. linteus mycelium}

After sterilizing the cultivated fruiting body of $P$. linteus, a small piece of the stipe was inoculated onto a potato dextrose agar medium $(39 \mathrm{~g}$, distilled water $=11)$. The developing colonies of the new hyphae (from the stipe) were transferred to malt agar in Petri dishes. The pure mycelia were subcultured for 2 weeks and grown in a $500 \mathrm{ml}$ Erlenmeyer flask in $125 \mathrm{ml}$ of medium containing $10 \mathrm{~g}$ sucrose, $30 \mathrm{~g}$ malt extract and $5 \mathrm{~g}$ yeast extract in 11 of distilled water. Each flask was seeded with 5 of the $10 \mathrm{~mm}$ plugs cut from the potato dextrose agar culture.

\section{Extraction procedure and separation of the $\mathrm{CHCl}_{3}$ and AcOEt extract of the mycelia}

After 5 weeks of culture (100 flasks) $\left(25^{\circ} \mathrm{C}\right.$, dark, 63 r.p.m.), the mycelia ( $990.55 \mathrm{~g}$, for $\mathrm{wt}$ ) were harvested with nylon cloth, homogenized with $\mathrm{MeOH}$ in a Waring blender and allowed to stand for 1 week at room temperature. The homogenate was filtered and the residue was reextracted with the same solvent. The filtrates were combined and the organic solvent was removed under reduced pressure. The concentrated methanolic extract was then diluted with water and partitioned with $\mathrm{CHCl}_{3}$ and AcOEt as follows: the residue was first extracted with $\mathrm{CHCl}_{3}$ (X2 in a total of 21 ), dried in vacuo and evaporated to dryness to afford the $\mathrm{CHCl}_{3}$ extract $\left(\mathrm{My} \mathrm{CHCl}_{3}\right.$, $20.99 \mathrm{~g}$ ). The resultant residue was then extracted with AcOEt (X4 in a total of $4.8 \mathrm{l}$ ), dried in vacuo and evaporated to dryness to afford the AcOEt extract (My EtOAc, $0.9557 \mathrm{~g}$ ). The $\mathrm{CHCl}_{3}$ extract $(20.99 \mathrm{~g})$ was first subjected to silica gel chromatography eluted with a toluene-AcOEt (19:1) mixture to afford fractions 1-10. Further purification of fraction $2(17.7 \mathrm{~g})$ was achieved by silica gel column chromatography to afford $2(3.59 \mathrm{~g})$. Fraction $4(450.3 \mathrm{mg})$ was recrystallized from $\mathrm{MeOH}$ to afford a colorless powder and mother liquid that were concentrated to afford fraction 4-1. Both (- )-trans- $\gamma$ monocyclofarnesol (1) (39.4 mg) and Phellidene E (3) (80.5 mg) were isolated from Fracton44-1 by HPLC (solvent: $90 \% \mathrm{MeOH}$, flow rate: $6.0 \mathrm{ml} \mathrm{min}^{-1}$ ).

1: Colorless oil; $[\alpha]_{\mathrm{D}}^{22}-6.76^{\circ} \quad(c=0.10, \mathrm{MeOH}) ;$ IR $(\mathrm{KBr})$ $v_{\max } \mathrm{cm}^{-1}: 3421,2927,2855,1643 ; \mathrm{UV}(\mathrm{MeOH}) \lambda_{\max } \mathrm{nm}(\log \varepsilon)$ : 204 (4.06); FAB-MS (positive) $\mathrm{m} / z: 222[\mathrm{M}]^{+}, 245[\mathrm{M}+\mathrm{Na}]^{+} ; 1 \mathrm{H}$ and 13C NMR data (Table 1); HR-FAB-MS (positive) $\mathrm{m} / z$ : Calcd for $\mathrm{C}_{15} \mathrm{H}_{26} \mathrm{O}[\mathrm{M}]^{+}=222.1984$; found $=222.1979$.

2: Colorless solid; $[\alpha]_{\mathrm{D}}{ }^{28}+11.7^{\circ} \quad\left(c=0.21, \mathrm{CHCl}_{3}\right)$; IR $(\mathrm{KBr})$ $v_{\max } \mathrm{cm}^{-1}: 3420,2920,1680,1645,1625,1600 ; \mathrm{UV}(\mathrm{MeOH}) \lambda_{\max } \mathrm{nm}$ $(\log \varepsilon): 250$ (4.38); EI-MS $m / z: 234[\mathrm{M}]^{+} ; 1 \mathrm{H}$ and 13C NMR (Table 1); HR-EI-MS $m / z$ : Calcd for $\mathrm{C}_{15} \mathrm{H}_{22} \mathrm{O}_{2}[\mathrm{M}]^{+}=234.1620$; found $=234.1624$.

3: Colorless solid; $[\alpha]_{\mathrm{D}}{ }^{28}+4.55^{\circ} \quad(c=0.22, \mathrm{MeOH})$; IR $(\mathrm{KBr})$ $\nu_{\max } \mathrm{cm}^{-1}:$ 3400, 2925, 1696, 1650, 1640; UV (MeOH) $\lambda_{\max }$ $\mathrm{nm}(\log \varepsilon$ ): 223 (4.23), 205 (4.21); FAB-MS (positive) $\mathrm{m} / z: 251$ $[\mathrm{M}+\mathrm{H}]^{+}, 273[\mathrm{M}+\mathrm{Na}]^{+}:{ }_{1} \mathrm{H}$ and $13 \mathrm{C}$ NMR data (Table 1); HR-FAB-MS (positive) $m / z$ : Calcd for $\mathrm{C}_{15} \mathrm{H}_{23} \mathrm{O}_{3}[\mathrm{M}+\mathrm{H}]^{+}=251.1647$; found $=251.1637$.

\section{CONFLICT OF INTEREST}

The authors declare no conflict of interest.

\section{ACKNOWLEDGEMENTS}

We would like to thank Dr Masato Iwatsuki, from the Kitasato Institute for Life Sciences, Kitasato University, for his advice on ECD measurements. We would also like to thank Dr K Nagai and Ms Noriko Sato from Kitasato University for their assistance in various instrumental analyses. We would like to thank Dr Noritada Kobayashi from Biomedical Laboratory, Division of Biomedical Research, Kitasato University Medical Center, for his support of measurement of antimicrobial activity. This study was supported in part by Kitasato University Research Grant for Young Researchers.

1 Feng, Z. \& Weinberg, A. Role of bacteria in health and disease of periodontal tissues. Periodontol. 2000 40, 50-76 (2006)

2 Liu, Y.-C. G., Lerner, U. H. \& Teng, Y.-T. A. Cytokine responses against periodontal infection: protective and destructive roles. Periodontol. $2000 \mathbf{5 2}$, 163-206 (2010).

3 Berger, K. J. \& Guss, D. A. Mycotoxins revisited: part II. J. Emerg. Med. 28, 175-183 (2005)

4 Chen, H., Tian, T., Miao, H. \& Zhao, Y. Traditional uses, fermentation, phytochemistry and pharmacology of Phellinus linteus: a review. Fitoterapia 113, 6-26 (2016).

5 Nakamura, T., Matsugo, S., Uzuka, Y., Matsuo, S. \& Kawagishi, H. Fractionation and anti-tumor activity of the mycelia of liquid-cultured Phellinus linteus. Biosci. Biotechnol. Biochem. 68, 868-872 (2004).

$6 \mathrm{Kim}, \mathrm{G} .-$ Y. et al. Proteoglycan isolated from Phellinus linteus induces toll-like receptors 2- and 4-mediated maturation of murine dendritic cells via activation of ERK, p38, and NF-kB. Biol. Pharm. Bull 27, 1656-1662 (2004).

7 Inagaki, N. et al. Inhibition of IgE-dependent mouse triphasic cutaneous reaction by a boiling water fraction separated from mycelium of Phellinus linteus. Evid. Based Complement. Alternat. Med. 2, 369-374 (2005).

8 Song, Y. S. et al. Anti-angiogenic, antioxidant and xanthine oxidase inhibition activities of the mushroom Phellinus linteus. J. Ethnopharmacol. 88, 113-116 (2003).

9 Hui, J., Li, H., Zhu, C. Y., Li, Q. J. \& Hu, F. Q. Comparative analysis of nutrients in fruit body and mycelia of Phellinus igniarius. Spec. Wild Econ. Anim. Plant Res. 2, 59-61 (2009)

$10 \mathrm{Qi}, \quad$ X. \& Wang, C.-L. Comparative analysis of bioactive components in fruit bodies of Phellinus linteus growing on six species of trees. Food Sci. 31, 199-201 (2010).

11 Kim, G.-Y., Park, H.-S., Nam, B.-H., Lee, S.-J. \& Lee, J.-D. Purification and characterization of acidic proteo-heteroglycan from the fruiting body of Phellinus linteus (Berk. \& M.A. Curtis) Teng. Bioresour. Technol. 89, 81-87 (2003).

12 Quang, D. N., Hashimoto, T. \& Asakawa, Y. Inedible mushrooms: a good source of biologically active substances. Chem. Rec. 6, 79-99 (2006).

13 Suzuki, K. T., Suzuki, N. \& Nozoe, S. Isolation and enzymic formation of trans- $\gamma$-monocyclofarnesol. J. Chem. Soc. D Chem. Commun. 527a (1971).

14 Castillo, A., Silva, L., Briones, D., Quílez del Moral, J. F. \& Barrero, A. F. Collective synthesis of natural products sharing the dihydro-y-ionone core. Eur. J. Org. Chem. 2015, 3266-3273 (2015).

15 Oritani, T., Niitsu, M., Kato, T. \& Yamashita, K. Isolation of (2Z, 4E)- $\gamma$-ionylideneethanol from Cercospora cruenta, a fungus producing (+)-abscisic acid. Agric. Biol. Chem. 49, 2819-2822 (1985)

16 Stonard, R. J., Trainor, D. A., Nakatani, M. \& Nakanishi, K. Additivity relation in the amplitudes of exciton-split circular dichroism curves arising from interactions between different chromophores and its application in structural studies. J. Am. Chem. Soc. 105, 130-131 (1983).

$17 \mathrm{Li}$, X.-C., Ferreira, D. \& Ding, Y. Determination of absolute configuration of natural products: theoretical calculation of electronic circular dichroism as a tool. Curr. Org. Chem. 14, 1678-1697 (2010)

18 Nugroho, A. E. \& Morita, H. Circular dichroism calculation for natural products. J. Nat. Med. 68, 1-10 (2014) 